\title{
Similarity of sun protection attitudes and behaviours within north Queensland peer groups
}

\author{
Torres Woolley and Petra Buettner
}

\section{Background}

Excessive exposure to ultra-violet radiation (UVR) significantly increases an individual's risk for developing both melanoma and non-melanoma skin cancer (NMSC). ${ }^{1-4}$ Reported incidence rates of skin cancer are among the highest in the world in North Queensland (NQ). ${ }^{5-6}$ These high rates of skin cancer can be at least partly explained by the high-risk environment. NQ is located in the tropics of Australia, and throughout most of the year it has extreme levels of solar UVR combined with cloudless and relatively unpolluted skies. Further, the predominantly Caucasian population has a genetic disposition to skin cancer, ${ }^{7}$ and a culture of enjoying recreational activities based around water or the beach, activities shown to be high risk for later development of skin cancer. ${ }^{8}$

During these activities, North Queenslanders should adequately protect themselves from the sun because of the extreme levels of overhead and water-reflected UVR. Since the 1980 s, the Australian SunSmart campaign has suggested an optimal sun protection strategy of covering up exposed skin areas through the use of wide-brimmed hats and protective clothing with long sleeves and collar and, for those areas of the skin not adequately covered, using a waterproof, broadspectrum sunscreen with a sun protection factor of at least $15,{ }^{9}$ which should be re-applied every two hours, or more frequently if perspiring or swimming. ${ }^{10}$ More recently, these messages have been altered to also include the wearing of sunglasses. 11

Many factors are known to influence an individual's use of optimal sun protection, including; season, comfort, convenience, social norms, planning and personal attitudes. ${ }^{12}$ Influence of peers and family on the sun exposure (sunbathing) habits of teenagers and adults has also been documented. ${ }^{13,14}$ Bandura proposes that the social environment has a significant effect on the way people behave, with most human behaviour being learned from observing others - through noting other people's attitudes, behaviours and the outcomes of those behaviours. ${ }^{13}$ Specifically, this Social Learning Theory proposes

\section{A fistaret}

Issue addressed: The study investigates whether the perceived sun protective practices of the peer group during a day-time recreational boat trip were associated with the sun protective attitudes and behaviours of individuals on the same boat.

Methods: Cross-sectional survey of recreational boat users conducted in Townsville, North Queensland, during the summer of 2003. One hundred and twenty-four of 134 boat users returning from a day trip agreed to participate, with 10 later excluded from analysis duc to either being the sole person on the boat or because they were in the sun for less than an hour between 9 am and $3 \mathrm{pm}(\mathrm{n}=114$, response rate $=92 \%)$.

Results: The more positively respondents perceived the sun protective behaviours of other people on the boat, the more likely they were to report that they: did not enjoy exposing their unprotected skin to the sun $(p=0.004)$; believed an occasional sunburn is not an acceptable risk ( $p=0.006)$; wore sunglasses on the trip $(p=0.002)$; wore a wide-brimmed hat together with a long-sleeved shirt and sunscreen $(p=0.006)$; and did not report reasons for neglecting to use sun protection $(p=0.019)$.

Conclusions: The perceived sun protection practices of the peer group majority were significantly associated with the sun protection practices of the observer.

Key words: Sun protection, health promotion, skin cancer, peer education.

Health Promotion journal of Australia 2009; 20:107-11

\section{Siv what}

Educating North Queenslanders about avoiding UVR-induced skin damage from social recreational sun activities should involve adapting sun protection messages to target peer and family social networks, and identifying peer leaders who can be used to model recommended sun protective practices. 
that if individuals observe a positive, desired outcome with the observed behaviour (e.g. other people avoiding sunburn by using sun protection), then they are more likely to imitate and adopt the behaviour themselves.

In addition, Bandura expanded in Social Learning Theory to suggest that learning will most likely occur if there is a close identification between the observer and the model; with identification allowing the observer to feel a one-to-one connection with the individual being imitated. ${ }^{16}$ Supporting this, recent evidence has shown that the influence of an individual's close circle of friends is a significant factor in health-related attitudes, and other studies have suggested that people generally adopt the attitudes of valued peers. ${ }^{17,10}$ As people are likely to go recreational boating with their more immediate friends and family, it is possible that this social environment may be influencing the sun-related attitudes and behaviours of individuals.

This study sought to identify whether the observed sun protective behaviours of the majority of other people on a recreational boating trip were associated with the sun-related attitudes and behaviours of the observer. This information may be applied to more targeted sun protection campaigns based on family or peer social networks.

\section{Methods}

\section{Participants}

The study had a cross-sectional design with a prospective 24-hour follow-up. Data were collected first by a face-to-face verbally administered questionnaire, then later by telephone after 24 hours. The survey was conducted in the city of Townsville, NQ (latitude 195, population 127,000) on three warm $\left(>30^{\circ} \mathrm{C}\right)$ and sunny Sundays between February and March 2003. During a typical Townsville sunny summer's day, measured UVB peaks in the middle of the day, but levels are at least one Standard Erythemal Dose (SED) between 9 am and $3 \mathrm{pm}$.' The SED is the proposed 'measure' for erythemally effective UVR exposure (equivalent to $100 \mathrm{~J} \mathrm{~m}^{2}$ of erythemally weighted irradiance), and is a standard measure that can be used for all individuals, regardless of skin type. ${ }^{19}$

The study population was adults $\geq 18$ years) who had undertaken a recreational boat trip. Only adults were invited to participate because of issues with obtaining consent from minors and the potential influence of parents on the sun protection practices of minors. Participants were approached after docking their boat at either the Townsville Sailing Club, or boat ramps at the Townsville Breakwater, South Townsville National Park, Bohle or Giru. Recruilment occurred between $11 \mathrm{am}$ and $5 \mathrm{pm}$, allowing participants to experience at least one hour in the sun between $9 \mathrm{am}$ and $3 \mathrm{pm}$ - the extreme period for UVR during the NQ summer. ${ }^{7}$
Of 134 boat users approached, 124 consented to participate. While all adults in a boat were invited to participate, on $83 \%$ of occasions data was obtained from only one member of the boating party, as usually the other person(s) was involved in placing the boat on their trailer and driving it from the busy boat ramp area. All but six returning boats that were approached had at least two people in the boat; the six people who were boating by themselves were asked to fill out the survcy, but were not included in the bivariate analyses. A further four people reported that they had not spent any time boating between the hours $9 \mathrm{~m}$ and $3 \mathrm{pm}$; these participants were later removed from the database. This resulted in a sample population of 114 participants for the bivariate analysis, with a response rate of $92 \%$. Ethical approval for the study was obtained from the James Cook University Ethics Committee, number H1334.

\section{Questionnaire}

Demographic questions included age, gender, and total years of life-time spent in NQ. Skin type, an index of sun-sensitivity representing the propensity to sunburn, was self-assessed according to Fitzpatrick's classification (scale I to IV from most sun sensitive to least sun sensitive Caucasian skin). ${ }^{20}$ Respondents also self-assessed the suntan level on their face by choosing from one of five categories: very light, light, moderate, dark or very dark.

With regards to the dependent variable, participants were asked to categorise how well the majority of other people on the boat protected themselves from the sun on the boat trip into either poor, OK or good use of sun protection. No definitions were included to assist participanls in categorising other people's sun protection practices into poor, OK or good, as accurate definitions would vary based on the time the boat was out on the water, how many times people re-applied sunscreen, if long-sleeved shirts were rolled up on the forearms, if their hat brim was more or less than seven centimetres, how long sun protection was actually used, elc. However, this question followed immediately after the sun behaviour question listing all recommended sun protection practices that should have assisted participants in making a more informed judgement.

Personal sun behaviours were self-assessed by questions to participants about their sun protection measures used. Specific questions asked whether or not participants used the following sun protective measures on the boat trip: a wide-brimmed hat, long-sleeved shirt, sunglasses and long pants; a 'yes' or 'no' response was obtained for each measure respectively. Three further questions then asked: if they applied sunscreen on the boat trip ('yes' or 'no' response) and if yes how many times; whether there was a canopy or covered area in use on the boat, and; if participants had any reasons why they did not use sun protection (if reasons were given, these were later dichotomised into a 'yes' or 'no' response). 
Experience with skin cancer was determined as the number of self-reported previous skin cancers. Sunburn arising directly from the boat trip was determined by self-report after 24 to 48 hours through telephone follow-up, as all participants were asked to provide a first name and contact telephone number. Sunburn was defined as "at lcast skin redness or tenderness after 24 hours."

A time scale was used to obtain data on sun exposure during the boat trip, which allowed the investigation of both the total time in the sun, and time during peak UVR hours between 9 am and 3 pm. Recent sun exposure was assessed by asking frequency of boat trips and hours of sun exposure on a typical workday in the previous week. Participants' beliefs relating to sun exposure and sun damage were assessed by 'yes' or 'no' answers to questions about: enjoyment of exposing their skin to the sun; if an occasional sumburn is an acceptable risk; if a boat canopy is adequate sun protection, and; if sun reflection off the water is a big problem.

While the questionnaire was not validated, a very similar questionnaire was piloted the year previously, with 81 recreational boat users as part of a small undergraduate student project investigating sunburn incidence. Further, many of the measures relating to sun protection, sun exposure, sun damage and demographics used in the present questionnaire were borrowed from a previous skin cancer survey administered by the authors to NQ men with a histologically diagnosed NMSC. ${ }^{21}$ As part of the validation process for this previous survey, five men from the target population were interviewed to ensure the phrasing and terminology of each question was well understood and questions were answered as intended, and analysis of a pilot study involving 30 participants showed at least moderate agreement for most items.

\section{Statistical Analysis}

Data were coded numerically and entered into SPSS release 14 for Windows. Table 1 shows a complete list of the variables as they were considered for statistical analysis. Numerical variables were described as mean values and standard deviations (SD) or median values and inter-quartile ranges (IQR) depending on their distribution.

Thble 1: Bivariate relationships between how north Queensland recreational boat users $(n=114)$ reported the sun protection behaviours of fellow boaters on the same boat, and their own sun behaviours, sun exposure and attitudes.

\begin{tabular}{|c|c|c|c|c|c|}
\hline & $\begin{array}{l}\text { Other people's } \\
\text { sun protection } \\
\text { was poor } \\
(n=46)\end{array}$ & $\begin{array}{l}\text { Other people's } \\
\text { sun protection } \\
\text { was okay } \\
(\mathbf{n}=48)\end{array}$ & $\begin{array}{l}\text { Other people's } \\
\text { sun protection } \\
\text { was good } \\
(n=20)\end{array}$ & $p$-value ${ }^{a}$ & $\begin{array}{c}\text { p-value } \\
\text { adjusted }^{b}\end{array}$ \\
\hline \multicolumn{6}{|l|}{ Demographics } \\
\hline My age in years (mean $\left.\pm S D^{3}\right)$ & $35.5 \pm 10.6$ & $35.0 \pm 10.4$ & $39.3 \pm 13.2$ & 0.320 & 0.375 \\
\hline My gender is male & $78.3 \%$ & $79.2 \%$ & $80.0 \%$ & 0.877 & 0.982 \\
\hline I have skin type I or II (Fizpatrick's classification) & $39.1 \%$ & $29.2 \%$ & $35.0 \%$ & 0.591 & 0.575 \\
\hline I have a "dark" suntan level & $28.3 \%$ & $10.4 \%$ & $15.0 \%$ & 0.098 & 0.084 \\
\hline I have had a previously diagnosed skin cancer & $10.9 \%$ & $25.0 \%$ & $25.0 \%$ & 0.106 & 0.225 \\
\hline Median number of previously diagnosed skin cancers $(\mathrm{IQR})^{b}$ & $0(0,0)$; range $0-8$ & $0(0,0.75) ;$ range 0.10 & $0(0,0.75)$; range 0.4 & 0.164 & 0.520 \\
\hline Median years spenl living in tropics (IQR) & $13.5(6.0,26.5)$ & $12.5(4.25,26.75)$ & $25.5(11.0,36.75)$ & 0.051 & 0.053 \\
\hline \multicolumn{6}{|l|}{ Sun exposure } \\
\hline Median hours spent in the sun on this boat trip (IQR) & $5.0(3.5,6.0)$ & $4.5(3.1,5.9)$ & $3.3(3.0,5.1)$ & 0.089 & 0.107 \\
\hline Median hours I typically spend in the sun at work (IQR) & $2.0(0.5,8.0)$ & $2.0(1.0,5.0)$ & $4.0(1.0,7.75)$ & 0.809 & 0.636 \\
\hline Median number of times I go boating per month (IQR) & $2.0(1.0,4.25)$ & $4.0(1.0,4.0)$ & $2.5(1.0,4.75)$ & 0.761 & 0.796 \\
\hline I expericnced sunbum as a result of the boat trip today & $51.4 \%$ & $47.5 \%$ & $58.3 \%$ & 0.878 & 0.956 \\
\hline \multicolumn{6}{|l|}{ Sun protective attitudes } \\
\hline "Sun reflection off the water is a big problem" & $97.8 \%$ & $95.8 \%$ & $100 \%$ & 1.000 & 0.974 \\
\hline "A canopy alone is not adequate sun prolection" & $69.8 \%$ & $72.3 \%$ & $80.0 \%$ & 0.466 & 0.525 \\
\hline "I do not cnjoy exposing my skin to the sun" & $50.0 \%$ & $68.8 \%$ & $90.0 \%$ & 0.006 & 0.004 \\
\hline "An occasional sunburn is not an acceptable risk" & $39.1 \%$ & $64.6 \%$ & $70.0 \%$ & 0.002 & 0.006 \\
\hline \multicolumn{6}{|l|}{ Sun protective behaviours on the boat trip } \\
\hline I wore a wide brimmed hat today & $45.7 \%$ & $4.3 .8 \%$ & $80.0 \%$ & 0.039 & 0.059 \\
\hline I wore a long sleeved shirt today & $23.9 \%$ & $31.3 \%$ & $60.0 \%$ & 0.009 & 0.046 \\
\hline I applied sunscreen today & $73.9 \%$ & $89.6 \%$ & $95.0 \%$ & 0.002 & 0.008 \\
\hline I wore a brimmed hat + long sleeved shirt + sunscreen & $8.7 \%$ & $14.6 \%$ & $50.0 \%$ & $<0.001$ & 0.006 \\
\hline I wore sunglasses today & $71.7 \%$ & $91.7 \%$ & $100 \%$ & 0.001 & 0.002 \\
\hline I wore long pants today & $10.9 \%$ & $10.4 \%$ & $20.0 \%$ & 0.437 & 0.539 \\
\hline Median number of times I re-applied sunscreen today $(|\mathrm{QR}|$ & $1.0(0.75,2.0)$ & $1.0(1.0,2.0)$ & $2(1.0,2.0)$ & 0.454 & 0.251 \\
\hline The boat I was on used a canopy today & $41.3 \%$ & $37.5 \%$ & $60.0 \%$ & 0.301 & 0.473 \\
\hline Ihad reasons why I did not use sun protection today & $41.3 \%$ & $37.5 \%$ & $5.0 \%$ & 0.013 & 0.019 \\
\hline
\end{tabular}


The bivariate associations between demographic variables, variables describing sun exposure, variables describing sun protective attitudes and behaviour, and how the respondent reported the sun protection behaviours of other people on the boat, were assessed with chi-squared tests for trend, unpaired ANOVA and non-parametric Kruskal-Wallis tests, as appropriatc. P-values were adjusted for the confounding effects of age and skin lype and for the effect of cluster sampling (primary sampling unit = boat). The multivariate adjustment was conducted using the survey commands of STATA (STATA cooperation, College Station, Texas, US).

\section{Results}

A total of 114 (response rate 92\%) NQ adults involved in recreational boating participated in the study. The mean age of the participants was 36 years ( $\mathrm{SD} \pm 11.1$ ), and most $(78.9 \%$ ) were male. Almost a third of participants (28.1\%) were out on a sailing boat, while the remaining (71.9\%) were in small motorboats.

Almost one-fifth (18.4\%) of participants reported having a dark $\tan$. Overall, $84.2 \%$ reported that they used sunscreen while boating, $50.9 \%$ wore a wide-brimmed hat, $33.3 \%$ wore a longsleeved shirt, $85.1 \%$ wore sunglasses, $12.3 \%$ wore long pants, and $18.4 \%$ wore the recommended sun protection combination of a long-sleeved shirt, wide-brimmed hat and sunscreen.

Overall, $40.4 \%$ of participants reported that they perceived the sun protective behaviours of others on the boat as poor, $42.1 \%$ as okay, and $17.5 \%$ as good. The more positively the respondents perceived the sun protective behaviours of other people on the boat, the more likely they were themselves to report that they did not enjoy exposing their unprotected skin to the sun ( $p=0.004$ ), did not consider an occasional sunburn is an acceptable risk $(p=0.006)$, to wear sunglasses on the trip ( $p=0.002)$, to wear a wide-brimmed hat together with a long-sleeved shirt and sunscreen $(p=0.006)$, and not report barriers to sun protection $(p=0.019)$ (Table 1).

\section{Discussion}

The study provides evidence that the social environment during recreational boating trips, likely based around family or peer group friendships, is associated with an individual's sun-related attitudes and behaviours. An individual's decision to engage in particular behaviours has long been known to be associated with the social environment. ${ }^{15}$ People tend to form friendships with others who exhibit similar behaviours, attitudes or mode of dress; in turn, the peer group will also influence member's attitudes, behaviours and mode of dress. ${ }^{22}$ As three or four people together are generally enough to produce very strong real or imagined peer pressure effects from the social group, ${ }^{23}$ it is feasible that the social environment on small boats, which consisted of between two and four people, was having an influence on people's sun-related attitudes and behaviours.
Association should never be confused with causality, but if the results of this study are reflective of an underlying relationship between friendships and sun-related altitudes and behaviours, then they might also be used to improve sun protective behaviours. For example, the delivery of sun protection messages or health promotion initiatives could be adapted to include group efforts aimed at peer and family social networks. In addition, new intervention strategies that identify and involve 'peer leaders' to model optimal sun protection behaviours might lead to better sun protective behaviours by the peer group, as the social environment is known to reinforce the adoption of new behaviours. ${ }^{15}$

An appropriate person to be used as a 'peer leader' with respect to improving sun behaviours on recreational boat trips may be the owner of the boat, as they are more easily identifiable and go out every time. People with previously diagnosed skin cancer might also be good peer leaders for a sun protection intervention. If the boat owner or other appropriate peer leaders can be educated to be more concerned about skin cancer, wear recommended sun protection, remind others to bring sun protection for the trip, and keep sunscreen and spare brimmed hats and long-sleeved shirts on the boat, then perhaps others on the boat may become more concerned about better protecting themselves, and maintaining these practices over time.

The social environment has already been used successfully in various health promotion efforts to improve the health behaviours of individuals: spreading health-promoting behaviours among older people, ${ }^{24}$ increasing the fruit and vegetable intake of children, ${ }^{25}$ improving worker's use of personal protective equipment, ${ }^{26}$ and getting people to quit smoking. ${ }^{27}$ Use of peer leaders has also been shown to be effective for skin cancer prevention, at least in the short-term, in another high-risk, recreational setting in the US. ${ }^{28}$ Use of recommended sun protection was increased by patrons attending public swimming pools through a multicomponent intervention using peer leaders (lifeguards), skin cancer education and distribution of free sunscreen; though frequency of protective behaviours had started to decline by the end of the one-month intervention. ${ }^{28}$

While the authors acknowledge that using peer leaders and adapting sun protection messages or skin cancer health promotion initiatives to target peer and family social networks is a new approach and would likely require significant resources, given the high incidence of skin cancer in NQ, these results at least provide an interesting alternative foundation for addressing this important public health issue.

This study has several limitations. The sun protection practices of the individual who participated in the study and of their peers on the boat were subjectively assessed, and as a 
consequence, the resulting relationships between these two groups might be over-estimated. In addition, generally only one of the peer group members per boat was interviewed; for a full understanding of the peer group, each member of the group may need to have been interviewed, though this would have been time-consuming, required more interviewers and a different timing of the interviews. Future studies are recommended to confirm the suggested relationships in this study. Finally, caution is required for application of these findings to a wider audience; boaters were mostly male, and it is uncertain whether these findings are applicable to a predominantly femalc recreation group.

Notwithstanding these limitations, selection bias for both sailingboat and motor-boat users was unlikely; only one sailing club operates in the Townsville area and most members participated, and data was collected from all four major motor-boat ramps within 50 kilometres of the Townsville city. Furthermore, recall bias would likely be minimal, as sun protection and sun behaviour information was obtained immediately after participants returned from the boat trip. Misinformation bias is also unlikely to significantly affect the sludy, as almost half the respondents reported using less than optimal sun protection, about half reported experiencing sunburn as a result of the trip, and about $40 \%$ reported that other people in their boat generally used poor sun protection practices.

In conclusion, educating North Queenslanders about avoiding UVR-induced skin damage as a result of participating in social recrealional sun activities should involve adapting sun protection messages to target peer and family social networks, and identifying peer leaders who can be used to model recommended sun protective practices.

\section{Acknowledgement}

This study was supported by the Parkes Bequest, James Cook University, Townsville. Torres Woolley was the George Roberts PhD Scholar for North Queensland, granted by the Queensland Cancer Fund, Brisbane, between 1998 and 2001.

\section{References}

1. Rosso S, Zanetti R, Martinez C, et al. The multicenter south European study "Helios" II: different sun exposure patterns in the aetiology of basal cell and squamous cell carcinomas of the skin. Br / Cancer. 1996;73:1447-54.

2. Armstrong $B K$, Kricker $A$. The epidemiology of UV induced skin cancer. I Photochem Photobiol B. 2001;63:8-18.
3. Gallagher RP, Hill CB, Bajdik CD, et al. Sunlight exposure, pigmentary factors, and risk of nonmelanocytic skin cancer. I. Basal cell carcinoma. Arch Dermatol. 1995:131:157-63.

4. Gallagher RP, Hill CB, Bajdik CD, et al, Sunlight exposure, pigmentary factors, and risk of nonmelanocytic skin cancer. II. Squamous cell carcinoma. Arch Dermatol. 1995;131:164-9.

5. Buettner $P G$, Raasch $B A$. Incidence rates of skin cancer in Townsville, Australia. Int / Cancer. 1998;78:587-93. Erralum in: Int / Cancer. 2001:93:302-3.

6. Staples $M$, Elwood $M$, Burton $R$, et al. Non-melanoma skin cancer in Australia: 2002 national survey and trends since 1985. Med / Aust. 2006;184(1):6-10.

7. Bernhard C. Mayer B, Seckmeyer G, Moise A. Measurements of spectral solar UV irradiance in tropical Australia. Journal of Ccophysical Research. 1997;102:8719-30.

8. Rosso S, Zanetti R, Martinez C, et al. The multicenter south European study "Helios" II: different sun exposure patterns in the actiology of basal cell and squamous cell carcinomas of the skin. Br J Cancer. 1996;73:1447-54.

9. Borland R. Public Awareness and Reported Effects of the 1989-7990 SunSmart Campaign. SunSmart Evaluation Studies 2. Melbourne (AUST): Anti-Cancer Council of Victoria; 1997. p. 9-18.

10. Marks $R$. The use of sunscreens in the prevention of skin canccr. Cancer forum $1996 ; 20(3): 211-15$

11. The Cancer Council of Queensland [homepage on the Internet]. Brisbane (AUST): State Government of Queensland; 2008 [cited 2009 Mar 24] Information sheet: Personal Protection. Available from: http://www.cancerqld. org.au/

12. Cummings SR, Tripp MK, Hermann NB. Approaches to the prevention and control of skin cancer. Cancer Melastasis Rev. 1997;16:309-27.

13. Hoerster KD, Mayer JA, Woodruff SI, Malcarne V, Roesch SC, Clapp E. The influence of parents and peers on adolescent indoor tanning behavior: findings from a multi-city sample. / Am Acad Dermatol. 2007;57(6):990-7.

14. Keesling $B$, Friedman HS. Psychosocial factors in sunbathing and sunscreen use. Health Psychology. 1987;6(5):477-93.

15. Bandura A. Social Learning Theory. Englewood (NJ): Prentice-Hall; 1977

16. Bandura A. Organizational application of Social Cognitive Theory. Australian Journal of Management. 1988;13(2):275-302.

17. Christakis $N$, Fowler J. The spread of obesity in a large social network over 32 years. N Engl/ Med. 2007; 357(4):370-9.

18. Puhl RM, Schwartz MB, Brownell KD. Impact of perceived consensus on stereotypes about obese people: A new approach for reducing bias. Health Psychol. 2005; 24(5):517-25.

19. Diffey BL, Jansen CT, Urbach F, Wulf HC. The Standard Erythemal Dose: A new photobiological concept. Photodermatol Photoimmunol Photomed. $1997 ; 13: 64-6$

20. Fitzpatrick TP. The validity and practicality of sun-related skin types I through VI. Arch Dermatol. 1988;124:869-71

21. Woolley T, Buettner PG, Lowe JB. Sunburn in Australian men with a history of non-melanoma skin cancer. Am J Health Behav. 2003;27(3):195-207.

22. Goldstein JW, Rosenfeld HM. Insccurity and preference for persons similar to oneself. J Pers. 1969;37(2):253-68.

23. Gerard HB, Wilhelmy RA, Conolley ES. Conformity and group size. I Pers SOC Psychol. 1968;8(1):79-82.

24. Thanakwang K, Soonthorndhada K. Family relations and health-promoting behaviour among older people in Nan province. 1 Med Assoc Thai. 2008:91(7):1102-8.

25. De Bourdeaudhuij I, te Velde S, Brug J, et al. Personal, social and environmental predictors of daily fruit and vegetable intake in 11 -year old children in nine European countries. Eur J Clin Nutr. 2008;62(7):834-41.

26. Torp S, Grøgard JB, Moen BE, Brătveit $M$, et al. The impact of social and organizational factors on workers' use of personal proteclive equipment: a multilevel approach. J Occup Environ Med 2005;47(8):829-37.

27. Sorensen C, Emmons K, Stoddard AM, Linnan L, Avrunin J. Do social influences contribute to occupational differences in quiting smoking and attitudes towards quitting? Am / Healih Promot. 2002:16(3):135-41

28. Lombard D, Neubauer TE, Canfield D, Winett RA. Behavioural communily intervention to reduce the risk of skin cancer. I Appl Behav Anal. 1991;24:677-86.

\section{Hithos}

Torres Woolley and Petra Buettner, James Cook University, School of Public Health, Tropical Medicine and Rehabilitation Sciences, Skin Cancer Research Group, Townsville Queensland

Corrognondence

Torres Woollev, Skin Cancer Research Group, School of Public Health, Tropical Medicine and Rehabilitation Sciences, James Cook

University, Townsville Queensland 4817.Fax:47962567; e-mail: torres.woollcy@jcu.edu.au 